\title{
Evaluation of Effect of Blue Light on Decontamination of Tooth Brushes
}

\author{
Priyanka Agrawal ${ }^{1}$, Navinchandra M. Kaore ${ }^{2}$, Shilpa N. Kaore ${ }^{3}$ \\ ${ }^{1}$ Raipur Institute of Medical Sciences, Raipur, Chhattisgarh, India. ${ }^{2}$ Department of Microbiology, AIIMS, Bhopal, \\ Madhya Pradesh, India. ${ }^{3}$ Department of Pharmacology, AIIMS, Bhopal, Madhya Pradesh, India.
}

\section{ABSTRACT}

\section{BACKGROUND}

Oral health is the integral part of good general health and toothbrushes are the most common and vital component of daily maintenance of oral hygiene used for prevention of oral diseases. Toothbrushes used routinely are known to get contaminated over time by pathogenic organisms. Retention and survival of microorganisms on toothbrush is a possible cause of re-contamination of the mouth. Various approaches have been tried for decontamination of the tooth brushes mainly involving disinfectants. Blue light with wavelength of $450 \pm 30 \mathrm{~nm}$ has been shown to exhibit a broad spectrum of antimicrobial effect. Thus, this study was planned to evaluate the antimicrobial properties of blue light for effective decontamination of toothbrushes against commonly isolated pathogenic microorganisms contaminating the toothbrushes along with determining the best exposure time for effective decontamination.

\section{METHODS}

In this cross-sectional analytical study, participants were enrolled after IEC approval in 3 groups based on duration of blue light exposure. Two different set of toothbrushes were given to participants, one to determine the contamination and other to see the effect of exposure to blue light for different durations on decontamination. Data was maintained and analysed using in Microsoft Office Excel with appropriate statistical tools.

\section{RESULTS}

The use of blue LED light emitting $450 \pm 30 \mathrm{~nm}$ wavelength used in our study has shown a significant reduction in microbial contamination by pathogenic and commensal organisms in the daily use of toothbrushes. The participants with an exposure of 30 minutes effectively with best results statistically were with 8 hours of exposure.

\section{CONCLUSIONS}

Study suggests that exposure of blue light with wavelength of $450 \pm 30 \mathrm{~nm}$ can be effectively used to routinely decontaminate the toothbrushes against pathogenic microbes. Thus, causing them to absorb violet/blue light and subsequently lead to the production of cytotoxic reactive oxygen species (ROS) that can inactivate microbes.

\section{KEY WORDS}

Blue Light, Phototherapy Treatment, Decontamination, Tooth Brushes, Reactive Oxygen Species
Corresponding Author: Dr. Navinchandra M. Kaore, Additional Professor, AIIMS, Saket Nagar, Bhopal-462020, Madhya Pradesh, India. E-mail: nckaore@gmail.com

DOI: $10.14260 /$ jemds $/ 2022 / 6$

How to Cite This Article: Agrawal P, Kaore NM, Kaore SN. Evaluation of effect of blue light on decontamination of tooth brushes. J Evolution Med Dent Sci 2022;11(01):27-32, DOI: $10.14260 /$ jemds $/ 2022 / 6$

Submission 29-11-2021,

Peer Review 02-01-2022,

Acceptance 08-01-2022,

Published 13-01-2022.

Copyright (C) 2022 Priyanka Agrawal et al. This is an open access article distributed under Creative Commons Attribution License [Attribution 4.0 International (CC $B Y 4.0)]$ 


\section{BACKGROUND}

Oral health is the integral part of good general health and toothbrushes are the most common and vital component of daily maintenance of oral hygiene used for prevention of oral diseases. Colonization of the toothbrushes stored in unhygienic condition by potential pathogenic microbes poses a great risk of infections being caused by brushing. ${ }^{1}$ Tooth brushes are the most commonly used oral hygiene aid to promote oral health and prevent dental diseases. Unfortunately, proper care of toothbrush is often neglected and is kept in bathrooms which are a good place to harbour millions of micro-organisms. ${ }^{2}$

Toothbrushes used routinely are known to get contaminated over time by pathogenic organisms causing infections in oral cavity or elsewhere. Retention and survival of micro-organisms on toothbrush after brushing represents a possible cause of re-contamination of the mouth. Storage of the toothbrushes in a wet condition in attached toilet bathrooms or elsewhere propagates the growth of microorganisms which may harm the users. Micro-organisms such as Streptococci, Staphylococcus, Escherichia coli and Lactobacilli are implicated to cause dental caries, gingivitis, stomatitis, infective endocarditis and various diarrheal and fungal diseases in an individual affecting both oral and general health.3.4

The various approaches have been tried for decontamination of the tooth brushes mainly involving disinfectants. The increasing number of antibiotic resistant strains of microorganisms makes it even more important to develop antibiotic-free alternative treatments for decontamination of toothbrushes. ${ }^{5}$ Blue light, which covers the spectrum from 400 to $470 \mathrm{~nm}$ wavelength, is having intrinsic antimicrobial properties possibly attributed to the presence of the naturally occurring endogenous photosensitizing chromophores (i.e. photosensitizers) in microbial cells. ${ }^{3}$ The endogenous photosensitizers absorb violet/blue light and subsequently lead to the production of cytotoxic reactive oxygen species (ROS) that can inactivate microbes. ${ }^{6}$

Blue light has been shown to exhibit a broad spectrum of antimicrobial effect against bacteria and fungi, although generally the gram-positive bacteria are considered more susceptible to blue light than gram negative bacteria. ${ }^{7}$ Blue light has clinical application for treatment of acne, wound infection. Blue light is also a promising candidate for the control of problematic microorganisms in the clinical setting e.g., the disinfection of air and exposed surfaces. ${ }^{8}$

Thus, this study was to evaluate the antimicrobial properties of blue light with wavelength of $450 \pm 30 \mathrm{~nm}$ for effective decontamination of toothbrushes against commonly isolated pathogenic microorganisms contaminating the toothbrushes along with determining the best exposure time for effective decontamination.

\section{METHODS}

This analytical observational study was carried out in Department of Microbiology, attached to a Medical Institute in Central India over a period of 2 months after due approval from Institutional Ethics Committee (IEC) with an approval letter no. RIMS/ADMIN/261-A/2019 Dated 11.07.2019.

By a convenient sampling method around 45 consenting medical students of either gender, residing in campus of the medical institute and agreeing to abide by the protocol of study were enrolled keeping in view the dropout rate of 25 to $30 \%$. After informed consent all participants were provided with two newly packed and sealed tooth brushes, one red and other blue. Red brush was used as a routine by participants in morning and blue brush to be used in night. Red brush used by the participants was utilized to assess the normal as well as pathogenic microbes growing on participant's toothbrush and blue brush was used to assess the decontamination with blue light with varying exposure time. Enrolled participants were randomly divided into 3 groups with 15 study subjects in each group based on duration of blue light exposure for decontamination of the brushes.

1. Group I: 30 minutes of blue light exposure after use.

2. Group II: 2 hours of blue light exposure after use.

3. Group III: 8 hours of blue light exposure after use.
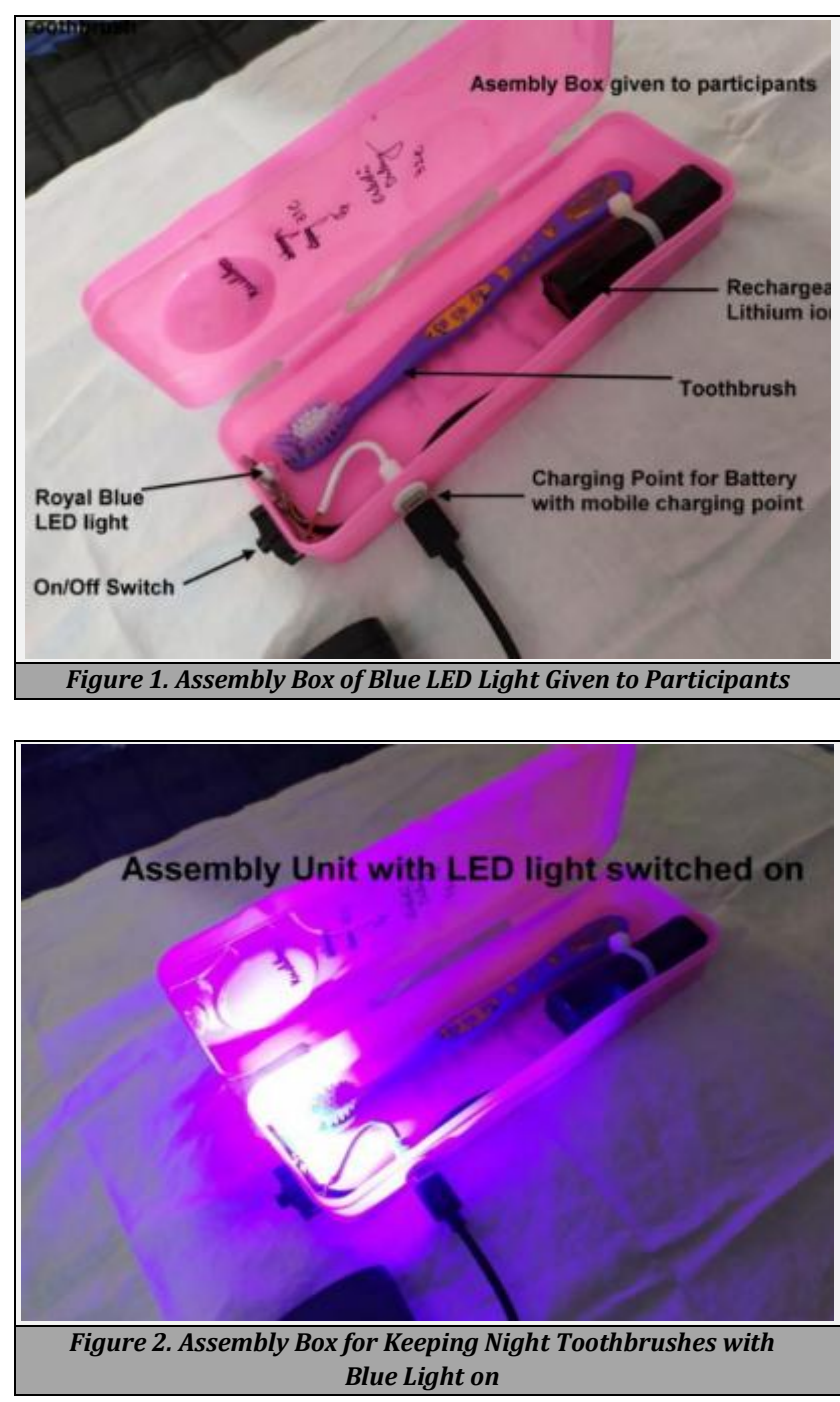

Unit Assembly for Exposure to Blue Light Small plastic containers fitted with blue LED light emitting $450 \pm 30 \mathrm{~nm}$ wavelength with 400 to $600 \mathrm{~mW}$ of average 
optical power were provided to the participants. The blue light was procured from Samarth Enterprises. The complete assembly with the heat sink to reduce the heat production, the on/off switch and a rechargeable lithium-ion battery for power supply was created taking help of the experts in the field. A charging point with a common mobile charging pin was also provided to charge the rechargeable battery. (Fig. 1 \& 2)

The participants were asked to keep the blue brush they used in night in the box provided for the particular duration according to the groups assigned. Both the red and blue brushes were collected after one month of use by the participants. The brushes thus collected were dipped (head side) in $3 \mathrm{ml}$ of sterile peptone water (PW) and vortexed. Then with the help of calibrated loop the PW was inoculated over blood agar \& MacConkey's agar (MA) and incubated aerobically at $37^{\circ} \mathrm{C}$ for 18 to $24 \mathrm{hrs}$. The bacterial colony count was noted and the colonies were identified using standard microbiological techniques. The peptone water was also subjected to microscopy by wet mount preparation for presence of any fungal elements which was then subjected to culture and morphological identification on slide culture and LPCB mount. ${ }^{9}$

The microbial contamination in red brush was noted in various storage condition and the blue brush was thus used to assess the decontamination with blue light with varying exposure time.

\section{Statistical Analysis}

Data was maintained in Microsoft Office Excel and appropriate statistical tools like tests of proportion \& test of significance like Pearson's chi square test was performed for analysis.

\section{RESULTS}

A total of 45 medical students between the age group of 19 to 25 years volunteered to participate in the present study with the gender distribution of $16 / 45$ (35.55\%) males against $29 / 45$ (64.44\%) females with a male to female ratio of $0.55: 1$. The 45 participants were divided into 3 groups depending on the exposure time to blue light. The gender wise distribution in all the three groups was as depicted in Table 1.

\begin{tabular}{|cccccc|}
\hline \multicolumn{2}{|c}{ Group I (n=15) } & \multicolumn{2}{c|}{ Group II (n=15) } & \multicolumn{2}{c|}{ Group III (n=15) } \\
Male & Female & Male & Female & Male & Female \\
$4(26.66 \%)$ & $11(73.33 \%)$ & $5(33.33 \%)$ & $10(66.66 \%)$ & $7(46.66 \%)$ & $8(53.33 \%)$ \\
\hline \multicolumn{4}{|c|}{ Table 1. Number and Percentage Distribution of Both the Genders in } \\
Group I, II \& III
\end{tabular}

In Group I, with 30 minutes of blue light exposure, there was no growth in both the toothbrushes for 2 participants. Results show that 4/15(26.66\%) participants have growth of Pseudomonas aeruginosa in morning toothbrush and no effect of the blue light for 30 minutes on the same. $7 / 15(46.66 \%)$ had growth of Enterobacteriaceae group of organisms in morning samples which showed significant reduction with exposure to blue light. Gram positive organisms like Streptococci and S. aureus also showed significant reduction with blue light in one participant each. (Table 2)

\begin{tabular}{|c|c|c|c|c|c|}
\hline 节 & $\begin{array}{c}\text { Growth of } \\
\text { Organisms } \\
\text { in Morning } \\
\text { Brush without } \\
\text { the } \\
\text { Use of Blue Light }\end{array}$ & $\begin{array}{c}\text { Colony } \\
\text { Count }\end{array}$ & $\begin{array}{c}\text { Growth on } \\
\text { Blue } \\
\text { Light } \\
30 \\
\text { Minutes }\end{array}$ & $\begin{array}{c}\text { Night } \\
\text { Brush } \\
\text { with } \\
\text { Exposure } \\
\text { for }\end{array}$ & $\begin{array}{c}\text { Colony } \\
\text { Count }\end{array}$ \\
\hline 1 & P. aeruginosa & $>10^{5}$ & P. aert & ginosa & $>10^{5}$ \\
\hline 2 & P. aeruginosa & $>10^{5}$ & P. aert & ginosa & $>10^{5}$ \\
\hline 3 & Citrobacter spp. & $>10^{5}$ & No gr & owth & NG \\
\hline 4 & Enterobacter spp. & 20 & Enterob & icter spp. & 10 \\
\hline 5 & S. aureus & 20 & No gl & owth & NG \\
\hline 6 & P. aeruginosa & $>10^{5}$ & P. aeru & ginosa & $>10^{5}$ \\
\hline 7 & Klebsiella & $>10^{5}$ & Kleb & siella & 100 \\
\hline 8 & Klebsiella + E. coli & 10 & No gl & owth & NG \\
\hline 9 & Klebsiella & 10 & No gl & owth & NG \\
\hline 10 & Streptococci & NG & No gr & owth & NG \\
\hline 11 & P. aeruginosa & $>10^{5}$ & P. aert & ginosa & $>10^{5}$ \\
\hline 12 & E. coli & $>10^{5}$ & No gl & owth & NG \\
\hline 13 & E. coli & $>10^{5}$ & No gi & owth & NG \\
\hline 14 & No growth & NG & No gr & owth & NG \\
\hline 15 & No growth & NG & No gi & owth & NG \\
\hline \multicolumn{6}{|c|}{$\begin{array}{l}\text { Table 2. Commensal Flora and the Growth of Microbial Contaminant } \\
\text { on Group I with and without the Use of Blue Light for } 30 \text { Minutes }\end{array}$} \\
\hline \multicolumn{6}{|c|}{ NG: No growth } \\
\hline
\end{tabular}

For Group II, with 2 hours of blue light exposure which exposed the night brush for 2 hours there was no growth in both the toothbrushes for 7 participants. 1/15 (6.66\%) participants showed growth of Pseudomonas aeruginosa in morning toothbrush with significant reduction to 9 colonies from more than $10^{5}$ colonies with exposure to blue light. 4/15 (26.66\%) had growth of Enterobacteriaceae group of organisms in morning samples which showed complete sanitation with blue light for 2 hours. 3/15 (20\%) samples showed gram positive organism, $S$. aureus with complete reduction with blue light for 2 hours. (Table 3)

\begin{tabular}{|c|c|c|c|c|}
\hline $\begin{array}{c}\text { Participant } \\
\text { No. }\end{array}$ & $\begin{array}{l}\text { Growth on Morning } \\
\text { Brush without the } \\
\text { Use of Blue Light }\end{array}$ & $\begin{array}{l}\text { Colony } \\
\text { Count }\end{array}$ & $\begin{array}{c}\text { Growth on Night } \\
\text { Brush Exposed to } \\
\text { Blue Light for } 2 \text { Hours }\end{array}$ & $\begin{array}{l}\text { Colony } \\
\text { Count }\end{array}$ \\
\hline 1 & No growth & NG & No growth & NG \\
\hline 2 & No growth & NG & No growth & NG \\
\hline 3 & Klebsiella & $>10^{5}$ & No growth & NG \\
\hline 4 & Klebsiella & $>10^{5}$ & No growth & NG \\
\hline 5 & P. aeruginosa & $>10^{5}$ & P. aeruginosa & 9 \\
\hline 6 & S. aureus & 3 & No growth & NG \\
\hline 7 & No growth & NG & No growth & NG \\
\hline 8 & No growth & NG & No growth & NG \\
\hline 9 & S. aureus & 10 & No growth & NG \\
\hline 10 & Klebsiella & $>10^{5}$ & No growth & NG \\
\hline 11 & No growth & NG & No growth & NG \\
\hline 12 & Klebsiella & $>10^{5}$ & No growth & NG \\
\hline 13 & No growth & NG & No growth & NG \\
\hline 14 & No growth & NG & No growth & NG \\
\hline 15 & S. aureus & 4 & No growth & NG \\
\hline \multicolumn{5}{|c|}{$\begin{array}{l}\text { Table 3. Commensal Flora and Growth of Microbial Contaminant on } \\
\text { Group II with and without the Use of Blue Light for } 2 \text { Hours }\end{array}$} \\
\hline \multicolumn{5}{|l|}{ NG: No growth } \\
\hline
\end{tabular}

\begin{tabular}{|c|c|c|c|c|}
\hline \multirow[b]{2}{*}{$\begin{array}{l}\text { Sr. } \\
\text { No. }\end{array}$} & \multirow[b]{2}{*}{$\begin{array}{l}\text { Growth on Morning } \\
\text { Brush without the Use } \\
\text { of Blue Light }\end{array}$} & \multicolumn{3}{|c|}{ Growth on Night Brush } \\
\hline & & $\begin{array}{c}\text { Colony } \\
\text { Count }\end{array}$ & $\begin{array}{l}\text { Stored with the Blue } \\
\text { Light Exposure for } 8 \\
\text { Hours }\end{array}$ & $\begin{array}{c}\text { Colony } \\
\text { Count }\end{array}$ \\
\hline 1 & Klebsiella & $>10^{5}$ & No growth & NG \\
\hline 2 & Klebsiella & $>10^{5}$ & No growth & NG \\
\hline 3 & Streptococci & $>10^{5}$ & Streptococci & 20 \\
\hline 4 & No growth & NG & No growth & NG \\
\hline 5 & S. aureus & 10 & S. aureus & 4 \\
\hline 6 & P. aeruginosa & $>10^{5}$ & P. aeruginosa & $10^{2}$ \\
\hline 7 & S. aureus & 12 & S. aureus & 4 \\
\hline 8 & No growth & NG & No growth & NG \\
\hline 9 & Klebsiella & $>10^{5}$ & Klebsiella & 11 \\
\hline 10 & E. coli & $>10^{5}$ & E. coli & $>10^{2}$ \\
\hline 11 & Gram positive bacilli & $>10^{5}$ & No growth & NG \\
\hline 12 & S. aureus & $>10^{5}$ & No growth & NG \\
\hline 13 & No growth & NG & No growth & NG \\
\hline 14 & No growth & NG & No growth & NG \\
\hline 15 & No growth & NG & No growth & NG \\
\hline & $\begin{array}{l}\text { Table 4. Commensal F } \\
\text { aminant on Group III }\end{array}$ & $\begin{array}{l}\text { ra and th } \\
\text { ith and wi } \\
\text { r } 8 \text { Hours }\end{array}$ & $\begin{array}{l}\text { ie Growth of Microbial } \\
\text { ithout the Use of Blue Li }\end{array}$ & ht \\
\hline
\end{tabular}


For Group III with 8 hours of exposure to blue light, 5/15 (33.33\%) participant showed no growth in both the morning and night tooth brush samples. 4/15 (26.66\%) participant showed growth of Enterobacteriaceae group of organisms with complete decontamination with blue light exposure. $1 / 15(6.66 \%)$ and $3 / 15(20 \%)$ participant showed growth of Streptococci and $S$. aureus respectively. Similarly, $1 / 15$ $(6.66 \%)$ each of pseudomonas and gram positive bacilli grown on the morning samples showed significant reduction and complete sanitation respectively as shown in Table 4 .

In all the groups the vortexed peptone water was centrifuged and was subjected to microscopy for presence of fungal elements. None of the samples had shown fungal elements in morning and night toothbrushes. If we look at the percent reduction in growth of pathogenic organisms in each group, it came out to be 60 percent each in Group I and III while 47 percent in Group II as shown in Table 5.

\begin{tabular}{|c|c|c|c|c|c|}
\hline & \multirow[b]{2}{*}{ 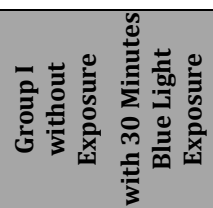 } & \multicolumn{2}{|c|}{ Group II } & \multicolumn{2}{|c|}{ Group III } \\
\hline & & 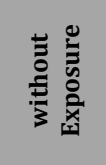 & 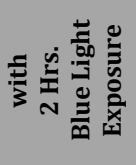 & 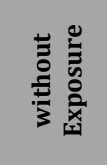 & 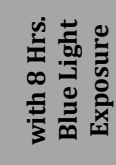 \\
\hline No growth & $\begin{array}{cc}2 & 2 \\
(13.33 \%) & (13.33 \%)\end{array}$ & $\begin{array}{c}7 \\
(46.66 \%)\end{array}$ & $\begin{array}{c}7 \\
(46.66 \%)\end{array}$ & $\begin{array}{c}4 \\
(26.66 \%)\end{array}$ & $\begin{array}{c}4 \\
(26.66 \%)\end{array}$ \\
\hline $\begin{array}{c}\text { Pathogenic } \\
\text { organisms }\end{array}$ & $\begin{array}{cc}13 & 04 \\
(86.66 \%) & (26.66 \%)\end{array}$ & $\begin{array}{c}08 \\
(53.33 \%)\end{array}$ & $\begin{array}{c}01 \\
(6.66 \%)\end{array}$ & $\begin{array}{c}10 \\
(66.66 \%)\end{array}$ & $\begin{array}{c}1 \\
(6.66 \%)\end{array}$ \\
\hline $\begin{array}{l}\text { Percent } \\
\text { reduction }\end{array}$ & $60 \%$ & & $47 \%$ & $60 \%$ & \\
\hline Table 5 & & & & & \\
\hline
\end{tabular}

The growth of pathogenic and commensal oral flora was compared against exposure to blue light for statistical significance using Pearson's chi square test in all the three groups as shown in Table 6 . With chi square value of 12.90 and $p$ value of 0.000329 , Group III has the best effect on decontamination of toothbrushes with blue light exposure time of 8 hours followed by Group I and later Group II.

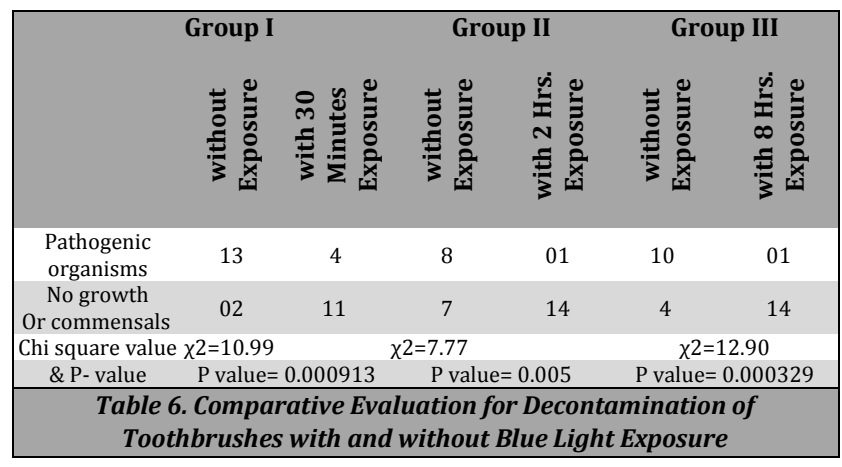

\section{DISCUSSION}

For hundreds of thousands of year humans did not brush their teeth. The development of the first tooth brush dates back to around $3000 \mathrm{BC}$, made by using frayed twigs. Around $1600 \mathrm{BC}$, the Chinese prepared "chew sticks" that were made from twigs of aromatic trees for freshening their breaths. In the ancient time the diet consisted of all natural and unprocessed foods which were safe as they did not contain chemicals or preservatives and had high nutritional values which protected their teeth from infections.
Tooth brushing is the most common method of oral hygiene management that plays an essential role in preventing dental caries and periodontal disease by removing the dental plaque on the tooth surface and appropriately stimulating the gingiva. However, since toothbrushes of healthy or diseased persons contain a large number of pathogenic microorganisms, they can cause respiratory, gastrointestinal, cardiovascular, and kidney problems. Moreover, the bristles contaminated with microorganisms resulting from daily use may cause a problem that can lead to oral infection. One toothbrush has millions to billions of germs, and contamination occurs from the initial use of the toothbrush. The more it is used repeatedly, the more it will be at risk for contamination. ${ }^{10}$

Much advancement has been made since in form of toothbrushes being developed of various material best suited for brushing the teeth and cleaning the interdental spaces. There is wide variety of toothbrushes available in the market majority of which are manual and some electric. The regular cleaning of the oral cavity exposes the toothbrushes to oral flora and epithelial tissue on buccal area and the tongue. Improper care of the toothbrush and the different storage condition exposes the toothbrush to contamination. ${ }^{1,4,10,11,12}$

Various chemical and physical methods have been tried by many researchers for effective decontamination of the toothbrushes. Blue light, which covers the spectrum from 400 to $470 \mathrm{~nm}$ wavelength, is having intrinsically antimicrobial properties possibly attributed to the presence of the naturally occurring endogenous photosensitizing chromophores (i.e. photosensitizers) in microbial cells. ${ }^{3}$ The endogenous photosensitizers absorb violet/blue light and subsequently lead to the production of cytotoxic reactive oxygen species that can inactivate microbes. ${ }^{6}$ Blue light has been shown to exhibit a broad spectrum of antimicrobial effect against bacteria and fungi, although generally the gram-positive bacteria are considered more susceptible to blue light than gram negative bacteria. ${ }^{7}$

Present study included 45 volunteer participants who were divided into three groups of 15 in each group depending on exposure time to blue light of wavelength of $450 \pm 30 \mathrm{~nm}$.

\section{Group 1}

Participants in age group of 19 to 25 years with blue light exposure time of 30 minutes with $26.66 \%$ males and $73.33 \%$ females. Microbial growth of organisms was detected in total on $13 / 15(86.66 \%)$ brushes tested in the study of which majority belonging to Enterobacteriaceae group $7 / 15$ (46.66\%). Brushes also showed pathogenic- bacteria Pseudomonas $4 / 15 \quad(26.66 \%)$ and Streptococci and Staphylococcus $1 / 15$ (6.66\%) each while 2/15 (13.33\%) showed no growth.

Exposure of blue light on toothbrushes showed no effect on pseudomonas. Enterobacteraceae group and gram positive organisms like streptococci and $S$. aureus showed significant reduction with blue light in participants.

\section{Group 2}

Participants in age group of 19 to 25 years with blue light exposure time of 02 hours with $33.33 \%$ males and $66.66 \%$ 
females. Microbial growth of organisms was detected in total on $8 / 15$ (53.33\%) brushes tested in the study of which majority belonging to Enterobacteriaceae group 4/15 (26.66\%) followed by Staphylococcus aureus 3/15 (20\%) and pseudomonas $1 / 15(6.66 \%)$ with $7 / 15$ (46.66\%) showed no growth.

After exposure of the night brush for 2 hours $1 / 15$ (6.66\%) participants showed significant reduction to 9 colonies from more than 105 colonies in Pseudomonas aeruginosa. Enterobacteriaceae group of organisms showed complete sanitation with blue light for 2 hours. Gram positive organism, $S$. aureus showed complete reduction with blue light for 2 hours.

\section{Group 3}

Participants in age group of 19 to 25 years with blue light exposure time of 08 hours with $46.66 \%$ males and $53.33 \%$ females. Microbial growth of organisms was detected in total on $10 / 15(66.66 \%)$ brushes tested in the study. Majority belonging to Enterobacteriaceae group 4/15 (26.66\%) followed by staphylococcus 3/15 (20\%), and pseudomonas, streptococci and gram positive bacilli 1/15 (6.66\%) each with 5/15 (33.33\%) showed no growth.

After exposure for 8 hours to the night brush participant in Group 3 showed growth of Enterobacteriaceae group of organisms with complete decontamination with blue light exposure. 1/15 (6.66\%) and 3/15 (20\%) participant showed growth of streptococci and $S$. aureus respectively which has also shown significant decontamination. Similarly, pseudomonas and gram positive bacilli grown on the morning samples showed complete sanitation.

Carranza FA Jr evaluated the wavelength and irradiation conditions that were most effective for growth inhibition of $P$. gingivalis without photosensitisers. Light irradiation at 405 $\mathrm{nm}$ specifically suppressed the growth of $P$. gingivalis, suggesting that visible blue light irradiation can eradicate periodontal pathogenic bacteria. ${ }^{2}$

Ah-Reum Shin et al. in Korea has tried various methods for decontamination of tooth brushes including chemical disinfectants and UV lights. They found out the various chemical disinfectants like chlorhexidine and povidone iodine were better disinfectants than UV steriliser for toothbrushes. ${ }^{13}$

Bjurshammer $\mathrm{N}$ et al. in their randomized control study on adjunctive daily use of blue light tooth brushing where blue light incorporated in the toothbrushes was done for 8 weeks to see effect of blue light on dental plaques and gingival inflammation. For all subject's dental plaque was reduced by $57 \%$, and a reduction in gingival inflammation was demonstrated by a decrease in gingival index (GI) with $46 \%$ and in bleeding on probing (BOP) with a decrease of $15 \%$. However, the amount of plaque was reduced by $62 \%$ in the blue light group and $51 \%$ in the control group. A toothbrush with a $450 \mathrm{~nm}$ LED did not show any statistically significant adjunctive effect of tooth brushing regarding reduction in measurements of dental plaque and gingival inflammation. ${ }^{14}$

This could be because of small time for which the plaque forming and gingivitis causing organisms are exposed to blue light while brushing. While in our study we have tried the exposure time to minimum of 30 minutes, 2 hours and maximum of 8 hours. With this exposure time we received a highly significant results with $\mathrm{p}$ value of less than 0.001 with more than 60 percent reduction in Group 1 and Group 3. (Table 5 \& Table 6)

Song et al. ${ }^{15}$ compared the antimicrobial effects of blue light on periodontal pathogens in planktonic and biofilm cultures. In the planktonic state, almost all bacteria were killed with 60 seconds of light exposure to $F$. nucleatum (99.1\%) and with 15 seconds to P. gingivalis (100\%). In the biofilm state, however, only the CFU of $P$. gingivalis demonstrated a decreasing tendency with increasing light exposure time, and there was a lower efficacy of phototoxicity to $P$. gingivalis as biofilm than in the planktonic state. 14 In our study the toothbrushes used by participants were stored by them at various places and have a tendency to form biofilms also. The increasing exposure time from 30 minutes to 8 hours has shown a definitive decrease in microbial contamination and in concordance with their study.

The use of blue LED light emitting $450 \pm 30 \mathrm{~nm}$ wavelength with 400 to $600 \mathrm{~mW}$ of average optical power used in our study has shown a significant reduction in microbial contamination by pathogenic and commensal organisms in the daily use of toothbrushes by the participants. This is also in accordance with the study carried out by Carranza FA Jr et al. ${ }^{2}$

\section{CONCLUSIONS}

This study established that phototherapy treatment in a toothbrush signals an effective approach of interests for maintaining daily oral hygiene, as it has proved to be a potential concomitant tool for preventing oral infections. Study suggests that exposure of blue light with wavelength of $450 \pm 30 \mathrm{~nm}$ can be effectively used to decontaminate the toothbrushes routinely against pathogenic microbes with an exposure of 30 minutes effectively with best results statistically with 8 hours of exposure.

\section{Limitations of the Study}

The study needs to be extrapolated further on larger sample size and for various time duration at an interval of half an hour increment to know the best time exposure of blue light. It will also be interesting to note the effect of the blue light on various material with which the bristles are made, both of which could not be done as it was a short-term project spanning just over 2 months.

Data sharing statement provided by the authors is available with the full text of this article at jemds.com.

Financial or other competing interests: None.

Disclosure forms provided by the authors are available with the full text of this article at jemds.com.

We would like to acknowledge the ICMR for choosing the important topic under short term studentship program. We would like to extend our sincere thanks Mr. Vijay Pusadkar who helped procure the royal blue LED with specific wavelength and Mrs. Rashmi Kulkarni of Zero Systems, Nagpur for preparing the Blue light unit for decontamination. We also extend our thanks to Mr. Khomlal Sahu, Technician Microbiology department for all the technical and official help in carrying out the study and all the participants who have participated enthusiastically extending full cooperation. 


\section{REFERENCES}

[1] Sukhabogii JR, Chandrashekar BR, Haritha N, et al. Microbial contamination of tooth brushes stored in different settings before and after disinfection with chlorhexidine-a comparative study. Journal of Young Pharmacists 2015;7(4):486-92.

[2] Carranza FA, Newman MG. A textbook of Clinical Periodontology. $8^{\text {th }}$ edn. Philadelphia: W. B. Saunders 1996: p. 493.

[3] Wetzel WE, Schaumburg C, Ansari F, et al. Microbial contamination of toothbrushes with different principles of filament anchoring. J Am Dent Assoc 2005;136(6):758-65.

[4] Karibasappa GN, Nagesh L, Sujatha BK. Assessment of microbial contamination of toothbrush head: an in vitro study. Indian J Dent Res 2011;22(1):2-5.

[5] Bush K, Courvalin P, Dantas G, et al. Tackling antibiotic resistance. Nat Rev Microbiol 2011;9(12):894-6.

[6] Wang Y, Wang Y, Wang Y, et al. Antimicrobial blue light inactivation of pathogenic microbes: State of the art. Drug Resist Updat 2017;33-35:1-22.

[7] Dai T, Gupta A, Murray CK. Blue light for infectious diseases: propionibacterium acnes, helicobacter pylori, and beyond? Drug Resist Updat 2012;15(4):223-36.

[8] Maclean M, MacGregor SJ, Anderson JG, et al. Inactivation of bacterial pathogens following exposure to light from a 405-nanometer light-emitting diode array. Appl Environ Microbiol 2009;75(7):1932-7.

[9] Collee J, Fraser A, Marmion B, et al. Mackie \& McCartney practical medical microbiology. $14^{\text {th }}$ edn. Elsevier 1996;387-98.

[10] Sowmya KR, Puranik MP, James JM, et al. Perceptions about toothbrush contamination and disinfection among dental students in Bengaluru city: a cross-sectional study. Indian J Dent Res 2017;28(6):646-9.

[11] Glass RT, Lare MM. Toothbrush contamination: a potential health risk? Quintessence Int 1986;17(1):3942.

[12] Chaturvedi R, Gautam SK, Kaur S et al. Assessment of microbial contamination of toothbrushes and factors influencing the same in medical students. J Evolution Med Dent Sci 2018;7(52):5565-70.

[13] Shin AR, Nam SH. Antimicrobien effects of various methods for the disinfection of contaminated toothbrushes. Biomed Res 2018;29(13):2880-4.

[14] Bjurshammar, N, Malmqvist S, Johannsen G, et al. Effects of adjunctive daily blue light toothbrushing on dental plaque and gingival inflammation-a randomized controlled study. Open Journal of Stomatology 2018;8(10):287-303.

[15] Song HH, Lee JK, Um HS, et al. Phototoxic effect of blue light on the planktonic and biofilm state of anaerobic periodontal pathogens. J Periodontal Implant Sci 2013;43(2):72-8. 